\title{
DENTAL FINDINGS OF PERSONS WITH OSTEOGENESIS IMPERFECTA IN VIETNAM
}

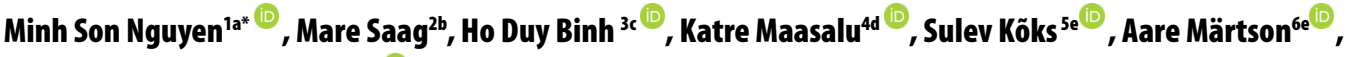 \\ Thi Thuy Le ${ }^{7 c}$, Triin Jagomägisf $\mathbb{C}$
}

\author{
'Faculty of Odonto-Stomatology, Danang University of Medical Technology and Pharmacy, Danang, Vietnam \\ ${ }^{2}$ Institute of Dentistry, University of Tartu, Tartu, Estonia \\ ${ }^{3}$ Hue University of Medicine and Pharmacy, Hue University, Hue, Vietnam \\ ${ }^{4}$ Department of Traumatology and Orthopedics, Institute of Clinical Medicine, University of Tartu, Tartu, Estonia, Clinic of Traumatology and Orthopedics, \\ Tartu University Hospital, Tartu, Estonia \\ ${ }^{5}$ Centre for Comparative Genomics, Murdoch University, Perth, Australia \\ ${ }^{6}$ Department of Traumatology and Orthopedics, Institute of Clinical Medicine, University of Tartu, Tartu, Estonia, Clinic of Traumatology and Orthopedics, \\ Tartu University Hospital, Tartu, Estonia \\ ${ }^{7}$ Faculty of Laboratory Medicine, Danang University of Medical Technology and Pharmacy, Danang, Vietnam \\ ${ }^{8}$ Institute of Dentistry, University of Tartu, Tartu, Estonia
}

\author{
aDDS, PhD; e-mail: minhson1883@gmail.com; ORCIDiD: https://orcid.org/0000-0001-9568-596X \\ bDDS, PhD, Professor; e-mail: mare.saag@ut.ee \\ 'MD, PhD, e-mail: binhthuybi@yahoo.com; ORCIDiD: https://orcid.org/0000-0003-1925-4601 \\ ${ }^{\mathrm{d} M D}$, PhD, Associate Professor; e-mail: katre.maasalu@kliinikum.ee; ORCIDiD: https://orcid.org/0000-0002-9428-0116 \\ eMD, PhD, Professor; e-mail: sulev.koks@perron.uwa.edu.au; ORCIDiD: https://orcid.org/0000-0001-6087-6643 \\ fMD, PhD, Professor; e-mail: aare.martson@kliinikum.ee; ORCIDiD: https://orcid.org/0000-0003-4857-484X \\ ${ }_{9}^{\mathrm{MDD}}$, PhD; e-mail: Itthuy@dhktyduocdn.edu.vn \\ ${ }^{h} D D S$, PhD, Associate Professor; e-mail: triin.jagomagi@ut.ee; ORCIDiD: https://orcid.org/0000-0003-4023-6256
}

\section{ABSTRACT}

do) https://doi.org/10.25241/stomaeduj.2020.7(2).art.2

Background Osteogenesis imperfecta $(\mathrm{OI})$ is the collective term for a heterogeneous group of connective tissue syndromes. The aim of the current study is to describe dental characteristics, including dentinogenesis imperfecta (DGI), dental wear, occlusal features, and dental caries experience of Vietnamese persons with OI. Methods The sample consisted of 74 individuals with Ol classified into type I $(n=25)$, type III $(n=24)$, and type IV $(n=25)$. All participants were examined for DGI through the evaluation of intrinsic color variation, dental wear using Hooper's index, occlusal features (including Angle's classification, overjet, overbite, crossbite) and dental caries experience by using the dmft/DMFT index.

Results DGI was found in $62.2 \%$ of the sample and was significantly related to OI type III and type IV $(p=0.019)$. Dental wear occurred in $36.5 \%$ and was equivalent among OI types. Angle Class III malocclusion was more prevalent in type III (66.7\%) and type IV (54.5\%) than in type I (37.5\%). High prevalence of reverse overjet $(60.3 \%)$, posterior crossbite (32.2\%), and missing teeth (23.3\%) were found in the Ol sample. The mean dmft/ DMFT score was 3.0/2.2. The dental findings related to dental wear, occlusal features, and dental caries did not show significant differences among type I, III, and IV.

Conclusion There was a high prevalence of DGI and dental wear in the Vietnamese OI sample. Occlusal features were related to a high prevalence of class III malocclusion, overjet, open bite, posterior crossbite, and missing teeth. Dental caries experience of persons with OI was at a moderate level.

\section{KEYWORDS}

Dental Care for Disabled; Dentinogenesis Imperfecta; Dental Occlusion; Osteogenesis Imperfecta.

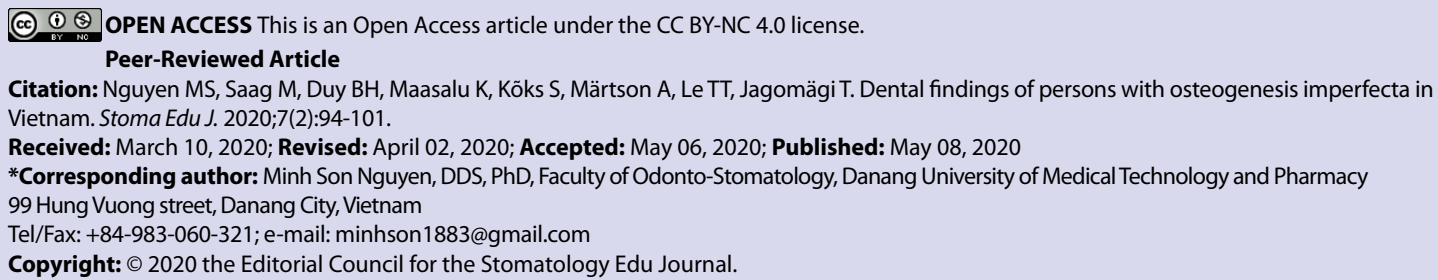




\section{INTRODUCTION}

Osteogenesis imperfecta (OI) is the collective term for a heterogeneous group of connective tissue syndromes. Seventeen mutated genes have been found related to OI syndromes [1,2]. The mutation incidence varies in different populations from $1 / 20,000$ to $1 / 10,000$ Ol cases [3-5].

The clinical classification of $\mathrm{OI}$ includes five types (type I-V) $[2,6]$. Type I is a mild phenotype with dominantly inherited $\mathrm{Ol}$ and blue sclerae; type II is related to perinatal lethality; type III results in progressive deformity throughout the lifespan; type IV is similar to type I, but sclerae are normal; and type V has mesh-like bone appearance due to calcification in inter-osseous membranes. In clinical studies, types I, III and IV are often mentioned to describe the clinical features of living individuals with OI syndrome. Collagen mutation may influence the dental-facial structures of individuals with OI. Previous studies indicated that more than $50 \%$ of individuals with Ol had class III malocclusions [7-9]. The OI syndromes cause not only maxillary deficiencies but also hypodontia $[8,10]$. Dentinogenesis imperfecta (DGI) and dental abnormalities are also observed in intraoral and radiologic examination of persons with $\mathrm{Ol}$, such alterations may result in premature wear of dental structure [10-13]. This suggests that OI has an impact on many oral conditions. Because it is a rare disease, many Ol studies focus on finding genetic mutations and on the treatment of bone fractures. There are still gaps in the scientific literature about the dental health of individuals with OI. In Vietnam although $\mathrm{OI}$ has been assessed medically [14], to the authors' knowledge, the dental aspects of Ol types have not been reported. Therefore, the aim of the current study is to investigate the dental characteristics of persons with $\mathrm{Ol}$, including dentinogenesis imperfecta, dental wear, dental caries experience, and malocclusion.

\section{MATERIALS AND METHODS}

\subsection{Study sample}

This is a cross-sectional study and the total sample consisted of 74 Ol persons aged 2-37 years (mean age $=10.6 \pm 7.1$, median age $=9.0$ ) from 34 healthcare centers across Vietnam. The OI diagnosis was based on Sillence's classification [5] and was confirmed by two orthopedic experts. OI participants or their legal representatives signed informed consent forms. The Danang University of Medical Technology and Pharmacy (No. 523/CN-DHKTYDDN) approved this study. All procedures were performed according to the World Medical Association Declaration of Helsinki.

\subsection{Examination of dentinogenesis imperfecta}

DGI was clinically diagnosed according to the Shields' classification [13]. The clinical examination of DGI was based on evaluating color variation, including lightness level, saturation, and hue of teeth, using the Vita System 3D-Master.

The system consists of six lightness level groups from 0 to 5 ( 0 =lightest, $5=$ darkest), five grades of color saturation (chroma) with a given score of 1 , $1.5,2,2.5$ and 3 , and three levels of hue ( $L=y e l l o w i s h$, $\mathrm{M}=$ intermediate hue, $\mathrm{R}=$ reddish). In the current study, the lightness level was divided into grades of lightness (score 0-2) and darkness (score 3-5); chroma was grouped into low saturation (score 1-2) and high saturation (score 2.5-3).

Tooth shades were determined in daylight in 5-7 seconds. In our study, DGI was confirmed by intrinsic color variation with teeth that were darker, had high color saturation and displayed a reddish hue.

\subsection{Measurement of dental wear}

A dental impression was taken for pouring a dental cast to measure tooth wear using a millimeter probe. Tooth wear was evaluated based on Hopper's index [15]. A six-point scale ( $0=$ no wear, $5=$ the most severe) was used to identify a tooth as having incisal/cuspal wear. The level of tooth wear was grouped into no/ mild and moderate/severe levels.

\subsection{Examination of dental caries}

The dental caries experience of persons with OI was recorded using the Decayed, Missing and Filled Teeth index for permanent teeth (DMFT) and for primary teeth (dmft). A decayed tooth was registered as presenting primary caries or secondary caries next to a filling. A missing tooth was a tooth that was extracted due to caries. A filled tooth was a tooth with restoration but without additional caries. The $\mathrm{dmft} / \mathrm{DMFT}$ score was the sum of decayed, missing and filled teeth.

\subsection{Analysis of occlusion}

Occlusal variables of $\mathrm{OI}$ dentition consisted of 10 variables including overbite, overjet, open bite, posterior crossbite, contact point displacement, midline diastema, molar Angle classification, incisal segment crowding, and incisal segment spacing.

\subsection{Calibration procedure}

The dental status of an OI person was examined twice on the same day by the first author (MSN) at local healthcare centers to ensuring reliability between the interval examination and inter-examiner. The Kappa value of 0.92 and 0.87 indicated high reliability of the clinical examination. The first author also conducted an analysis of occlusion and dental wear on dental casts. The calculated Kappa values were above 0.85 , indicating a high degree of intraexaminer and inter-analysis reliability.

\subsection{Statistical analysis}

Data entry and analyses were performed with the Statistical Package for the Social Sciences software 
ITable 1. Prevalence of dentinogenesis imperfecta and tooth discoloration in persons with osteogenesis imperfecta.

\begin{tabular}{|c|c|c|c|c|c|}
\hline \multirow{2}{*}{ Variable } & \multirow{2}{*}{$\begin{array}{c}\text { Total } \\
\mathrm{N}=74\end{array}$} & \multicolumn{3}{|c|}{ Ol classification } & \multirow{2}{*}{ p-value ${ }^{a}$} \\
\hline & & Type I & Type III & Type IV & \\
\hline \multicolumn{6}{|l|}{ Dentinogenesis imperfecta } \\
\hline No & 37.8 & 60.0 & 25.0 & 28.0 & \multirow{2}{*}{$0.019^{*}$} \\
\hline Yes & 62.2 & 40.0 & 75.0 & 72.0 & \\
\hline \multicolumn{6}{|l|}{ Tooth coloration } \\
\hline \multicolumn{6}{|l|}{ Lightness level } \\
\hline $0-2$ & 12.2 & 28.0 & 0 & 8.0 & \multirow{2}{*}{$0.008^{* b}$} \\
\hline 3-5 & 87.8 & 72.0 & 100 & 92.0 & \\
\hline \multicolumn{6}{|l|}{ Saturation (Chroma) } \\
\hline Low & 75.7 & 72.0 & 79.2 & 76.0 & \multirow[b]{2}{*}{0.842} \\
\hline High & 24.3 & 28.0 & 20.8 & 24.0 & \\
\hline \multicolumn{6}{|l|}{ Hue } \\
\hline Yellowish (L) & 10.8 & 4.0 & 8.3 & 20.0 & \multirow{3}{*}{0.418} \\
\hline Intermediate hue (M) & 79.7 & 88.0 & 79.2 & 72.0 & \\
\hline Reddish (R) & 9.5 & 8.0 & 12.5 & 8.0 & \\
\hline
\end{tabular}

${ }^{a}$ Chi-square test; b: Fisher's test

*Significant.

ITable 2. Prevalence of dental wear in persons with osteogenesis imperfecta.

\begin{tabular}{|c|c|c|c|c|c|}
\hline \multirow{3}{*}{ Dental wear } & \multirow{3}{*}{$\begin{array}{l}\text { Total } \\
\mathrm{N}=74\end{array}$} & \multicolumn{3}{|c|}{ Ol classification } & \multirow{3}{*}{$\mathrm{p}$-value } \\
\hline & & Type I & Type III & Type IV & \\
\hline & & $\mathrm{n}=25$ & $\mathrm{n}=24$ & $\mathrm{n}=25$ & \\
\hline \multicolumn{6}{|l|}{ Prevalence of OI persons with dental wear } \\
\hline No/mild & 63.5 & 55.6 & 69.6 & 63.6 & $0.652^{\mathrm{a}}$ \\
\hline Moderate/severe & 36.5 & 44.4 & 30.4 & 36.4 & \\
\hline \multicolumn{6}{|c|}{ Mean percentage of teeth showing wear in dentition } \\
\hline No/mild & 90.4 & 89.7 & 93.5 & 87.9 & $0.647^{b}$ \\
\hline Moderate/severe & 9.6 & 10.3 & 6.5 & 12.1 & \\
\hline
\end{tabular}

${ }^{a}$ Chi-square test; ${ }^{\mathrm{b}}$ ANOVA test.

version 17.0 (SPSS Inc., Chicago, IL, USA).

The Chi-square test and ANOVA test were used to identify the differences related to DGI, dental wear, occlusal features, and dmft/DMFT score among OI types I, III, and IV. An interval confidence level of $95 \%$ and a two-sided $p$-value of .05 were set for significant difference.

\section{RESULTS}

The study included 74 persons with Ol aged 2-37 years (50\% females and 50\% males). The distribution of clinical diagnoses was $33.8 \%$ type I $(n=25), 32.4 \%$ type III $(n=24)$, and $33.8 \%$ type IV $(n=25)$. Primary dentition was accounted for in $31.1 \%$ of the sample, mixed dentition was in $37.8 \%$, and permanent dentition was $31.1 \%$. Dentinogenesis imperfecta was found in $62.2 \%$ of the total sample. Prevalence of DGI was statistically more frequent in type III (75\%) and color variation, $72 \%$ dentition of type I, $92 \%$ of type IV, and $100 \%$ of type III were graded in darkness levels. Prevalence of high saturation was fairly equivalent among type I (28.0\%), type III (20.8\%), and type IV (24.0\%, $\mathrm{p}=0.842)$. The hue component of the total dentitions was $10.8 \%$ of yellowish, $79.7 \%$ of intermediate hue, and $9.5 \%$ of reddish.

There were no differences in hue components among Ol types ( $p=0.418$ ) (Table 1). Dental wear occurred in $36.5 \%$ of Ol individuals, of which $44.4 \%$ presented in type I, $30.4 \%$ in type III, and $36.4 \%$ in type IV. The mean percentage of the amount of tooth wear in dentition was found in $12.1 \%$ of type IV, $10.5 \%$ of type I, and $6.5 \%$ of type III. However, there were no differences in the distribution of tooth wear among three types of OI ( $p>0.05$, Table 2). Table 3 shows the characteristics of dentition associated with each type of OI. According to Angle's classification, class III was more prevalent in type III (66.7\%) and type 
ITable 3. Prevalence of occlusal features in persons with osteogenesis imperfecta.

\begin{tabular}{|c|c|c|c|c|c|c|}
\hline \multirow{2}{*}{\multicolumn{2}{|c|}{ Variable }} & \multirow{2}{*}{$\begin{array}{l}\text { Total } \\
\mathrm{N}=\mathbf{7 4}\end{array}$} & \multicolumn{3}{|c|}{ Ol classification } & \multirow[b]{2}{*}{ p-value } \\
\hline & & & $\begin{array}{l}\text { Type I } \\
n=25\end{array}$ & $\begin{array}{l}\text { Type III } \\
n=\mathbf{2 4}\end{array}$ & $\begin{array}{l}\text { Type IV } \\
n=25\end{array}$ & \\
\hline \multicolumn{7}{|l|}{ Angle's classification } \\
\hline & Class I & 27.1 & 43.8 & 23.8 & 18.2 & 0.231 \\
\hline & Class II & 18.6 & 18.8 & 9.5 & 27.3 & \\
\hline & Class III & 54.2 & 37.5 & 66.7 & 54.5 & \\
\hline \multicolumn{7}{|l|}{ Overbite $>3.5 \mathrm{~mm}$} \\
\hline & No & 80.7 & 64.3 & 90.5 & 81.8 & 0.155 \\
\hline & Yes & 19.3 & 35.7 & 9.5 & 18.2 & \\
\hline \multicolumn{7}{|c|}{ Increased overjet $>3.5 \mathrm{~mm}$} \\
\hline & No & 100 & 100 & 100 & 100 & - \\
\hline & Yes & 0 & 0 & 0 & 0 & \\
\hline \multicolumn{7}{|l|}{ Reverse overjet } \\
\hline & No & 39.7 & 60.0 & 33.3 & 31.8 & 0172 \\
\hline & Yes & 60.3 & 40.0 & 66.7 & 62.8 & 0.173 \\
\hline \multicolumn{7}{|l|}{ Posterior crossbite } \\
\hline & No & 67.8 & 75.0 & 57.1 & 72.7 & 042 \\
\hline & Yes & 32.2 & 25.0 & 42.9 & 27.3 & 0.424 \\
\hline \multicolumn{7}{|l|}{ Open bite } \\
\hline & No & 82.5 & 100 & 75.0 & 77.3 & בי1 0 \\
\hline & Yes & 17.5 & 0 & 25.0 & 22.7 & 0.133 \\
\hline \multicolumn{7}{|l|}{ Diastema } \\
\hline & No & 86.4 & 87.5 & 90.5 & 81.8 & 0.702 \\
\hline & Yes & 13.6 & 12.5 & 9.5 & 18.2 & \\
\hline \multicolumn{7}{|l|}{ Displacement $>2 \mathrm{~mm}$} \\
\hline & No & 66.1 & 75.0 & 52.4 & 72.7 & 0.251 \\
\hline & Yes & 33.9 & 25.0 & 47.6 & 27.3 & \\
\hline \multicolumn{7}{|c|}{ Incisal segment crowding } \\
\hline & No & 53.4 & 75.0 & 42.9 & 47.6 & 0.121 \\
\hline & Yes & 46.7 & 25.0 & 57.1 & 52.4 & \\
\hline \multicolumn{7}{|l|}{ Incisal segment spacing } \\
\hline & No & 66.1 & 62.5 & 76.2 & 59.1 & 0.466 \\
\hline & Yes & 33.9 & 37.5 & 23.8 & 40.9 & \\
\hline \multicolumn{7}{|l|}{ Missing teeth } \\
\hline & No & 76.7 & 76.5 & 76.2 & 77.3 & 0.996 \\
\hline & Yes & 23.3 & 23.5 & 23.8 & 22.7 & \\
\hline
\end{tabular}

Chi-square test; ${ }^{*}$ Significant.

IV (54.5\%) than in type I (37.5\%). No Ol persons had an increased overjet $(>3.5 \mathrm{~mm})$, but $60.3 \%$ of individuals had reverse overjet. Posterior crossbite occurred in $32.2 \%$ of the total Ol sample, of which 42.9\% presented in type III, $27.3 \%$ in type IV, and $25.0 \%$ in type I. High prevalence of incisal segment crowding (46.7\%), incisal segment spacing (33.9\%), displacement of tooth $>2 \mathrm{~mm}(33.9 \%)$, missing teeth (23.3\%), open bite (19.3\%) and diastema (13.6\%) were also found in the total sample, but no significant differences were observed among type I, III and IV ( $p>0.05$ ). Table 4 indicates dental caries experience within the Ol sample; the mean of the $\mathrm{dmft}$ and
DMFT score was $3.0 \pm 4.1$ and $2.2 \pm 4.6$ respectively. The dmft and DMFT scores were equivalent among types of OI $(p>0.05)$. None of the persons with $\mathrm{OI}$ received restorative treatment for decayed teeth, and none of the permanent teeth in type III and IV were extracted due to caries.

\section{DISCUSSION}

4.1. General information about Vietnamese persons with Ol. This is a preliminary study conducted in Vietnam to collect the dental characteristics of persons who suffer from OI. The total sample of our 
ITable 4. Mean score of dental caries components of primary and permanent teeth in osteogenesis imperfecta patients.

\begin{tabular}{|c|c|c|c|c|c|}
\hline \multirow{3}{*}{ Dental caries experience } & \multirow{3}{*}{$\begin{array}{l}\text { Total } \\
\mathrm{N}=74\end{array}$} & \multicolumn{3}{|c|}{ Ol classification } & \multirow{3}{*}{$\mathrm{p}$-value } \\
\hline & & Type I & Type III & Type IV & \\
\hline & & $\mathrm{n}=25$ & $n=24$ & $\mathrm{n}=25$ & \\
\hline \multicolumn{6}{|l|}{ Primary teeth } \\
\hline $\mathrm{dt}$ & $1.8 \pm 3.2$ & $0.9 \pm 2.0$ & $3.2 \pm 4.3$ & $1.7 \pm 3.1$ & 0.111 \\
\hline $\mathrm{mt}$ & $1.3 \pm 2.4$ & $1.1 \pm 2.8$ & $1.6 \pm 2.3$ & $1.2 \pm 2.0$ & 0.771 \\
\hline $\mathrm{ft}$ & 0 & 0 & 0 & 0 & - \\
\hline $\mathrm{dmft}$ & $3.0 \pm 4.1$ & $1.9 \pm 3.4$ & $4.9 \pm 4.4$ & $2.8 \pm 4.4$ & 0.119 \\
\hline \multicolumn{6}{|l|}{ Permanent teeth } \\
\hline DT & $1.7 \pm 2.4$ & $1.0 \pm 1.6$ & $2.3 \pm 2.9$ & $1.6 \pm 2.3$ & 0.295 \\
\hline MT & $0.3 \pm 1.8$ & $0.9 \pm 3.5$ & 0 & 0 & 0.272 \\
\hline FT & 0 & 0 & 0 & 0 & - \\
\hline DMFT & $2.2 \pm 4.6$ & $2.9 \pm 7.9$ & $2.3 \pm 2.8$ & $1.6 \pm 2.3$ & 0.753 \\
\hline
\end{tabular}

ANOVA test

$\mathrm{dt} / \mathrm{DT}$ : decayed teeth; $\mathrm{mt} / \mathrm{MT}=$ missing teeth; $\mathrm{ft} / \mathrm{FT}=$ filled teeth.

study was 74 Ol persons from thirty-four provinces that are home to approximately 60 million of the total population of Vietnam, meaning that the prevalence of Ol in Vietnam is estimated at 1/480,000. Our prevalence might be lower compared to the prevalence of $1 / 25,000-1 / 10,000$ reported in other countries [3-5]. Our study lacked information about Ol in the newborn infant group, and Ol's mild type might be undiagnosed in the general population; in addition, OI type II was excluded from the present study. Nonetheless, the distribution of Ol types in our study approached a range distribution of 39$79 \%$ for type I, $9-24 \%$ for type III, and $13-40 \%$ for type IV, as reported in previous studies [10,11,16,17]. Bisphosphonate therapy has good results in increasing the bone mineral density; however, most of our participants could not follow bisphosphonate therapy due to inaccessibility of adequate medical care, sustainment or counseling from the medical professionals.

\subsection{Dentinogenesis imperfecta and dental wear}

A high prevalence of DGI was found in Vietnamese with Ol. Our results were in accordance with a study by Majorana et al. [12] that indicated that $62.5 \%$ of an Italian Ol sample had DGl. Conversely, Malgrem [11] and Saeves [10] found that the prevalence of DGl in OI samples in Sweden and Norway was $41.5 \%$ and $19.0 \%$, respectively. Concerning DGI related to types of $\mathrm{Ol}$, our study is consistent with previous studies in showing DGI to be more prevalent in Ol type III than in type I and IV $[10,18]$, indicating that DGI is related to the severity of OI. DGI is a disorder of dentin formation causing deposition of dentine, obliteration of the pulp chamber and intrinsic discoloration. This could explain the finding that up to $80 \%$ of dentition in our Ol sample were graded as having a dark lightness level and yellow- red intermediate to reddish color. Our study found that $36.5 \%$ of Ol persons had dental wear. This is in line with previous investigations that found the prevalence of dental wear ranging from $37.5 \%$ to $66.5 \%$ in Ol samples [11,12]. Dental wear occurring in Ol person could be from DGI. Among DGI types of Shields' classification, DGI type I is associated with Ol because of the inherited disorders of collagen metabolism; whereas, DGI type II and III are mutations affecting the dentin sialophosphoprotein gene [13]. The mutations in COL1A1 and COL1A2 genes would cause DGI type I that teeth easily expose the abnormal dentine and were typically worn.

Approximately $10 \%$ of teeth in both dentitions were showed a severely worn condition in the current study. Preventive and restorative care of DGI and dental wear are important for Vietnamese OI persons. The treatment considerations are preservation of occlusal height, maintenance of oral function and esthetic needs. Nonetheless, most of Ol persons might not receive dental treatment because of the family economic hardship; thus, there is a need for more effective support for Ol persons to approach treatment to restore the harmony of the oral functions.

\subsection{Occlusal features}

Ol mutation not only has an impact on dental structure but also on dental occlusion. The findings of our study indicate that class III malocclusion presented in $54.2 \%$ of the sample, which was similar to $60-80 \%$ of class III malocclusion in investigations in Taiwan and Canada [7,9]. In the current study, class III malocclusion was more prevalent in OI type III compared to type IV and I. An individual with OI type III is described as having a triangular face, and this feature might be associated with class III malocclusion. High prevalence of class III in 
the Vietnamese Ol sample corresponded with the prevalence of $\mathrm{OI}$ persons having reverse overjet. Reverse overjet is a manifestation of disharmony between the maxilla and the mandible. In the current study, OI persons were likely to have deficient growth of the maxilla. The evidence was that a posterior crossbite presented in $25.0-42.9 \%$ of Ol types, with no Ol persons having an overjet $>3.5 \mathrm{~mm}$, a parameter indicating a protrusive maxilla. Our study was strongly supported by previous studies. Chang et al. [7] reported a shorter upper facial length in an Ol sample as compared to a healthy sample. By using the discrepancy index in orthodontic treatment, Rizkalla et al. [9] found Ol to be related with anterior and posterior crossbite. Scalia et al. [19] concluded that malocclusion of $\mathrm{Ol}$ was associated with $\mathrm{a}$ retrognathic maxilla. The impairment of maxilla growth could be from a lack of type I collagen due to mutation. In addition, the symptom of loose joints could be observed in severe cases of OI. When occurring in the temporomandibular joint, it can stretch more than normal and lead to abnormal jaw relations. The deficiency of maxillary length might also lead to teeth crowding. Our study found that both the prevalence of displacement of tooth $>2 \mathrm{~mm}$ and incisal segment crowding gradually increased from OI type I to type IV and type III. According to Sillence's classification for living OI patients, type I is the mildest form, whereas type III is the most severe form. Such severe deformities of OI type III and IV influenced the defective growth of the maxilla and might also be associated with disharmony of growth between the two jaws.

The evidence was that over $20 \%$ of people with OI type III and IV had an open bite in contrast with $0 \%$ of type I. Waltimo-Siren et al. [17] indicated that the gonial angle of Ol type I was 124.6 degrees, which was lower compared to the 126.3 degrees of Ol type III/IV. Similarly, Chang et al. [7] found a clockwise rotation of the mandible of Ol patients as compared to the control group. Such alterations in the mandible might be associated with an open-bite of occlusion in Ol patients.

The mutations of COL1A1 and COL1A2 in persons with $\mathrm{Ol}$ might prohibit tooth formation and development. In the current study, the prevalence of missing teeth was equivalent among Ol types, and it ranged from $22.7-23.8 \%$; that was much higher compared to $0.5-11.0 \%$ of missing teeth in the general population [20]. The findings related to missing teeth in our study are reinforced by previous Ol studies. Tooth agenesis was found in $17 \%$ of the Ol sample, including $11 \%$ hypodontia and $6 \%$ oligodontia [18].

Approximately $14 \%$ of individuals with OI type III had congenital missing teeth [21], and in our study, missing teeth accounted for $23.8 \%$ of Ol type III. The odds of having missing teeth among persons with Ol was more 2.0-4.7 times compared to the general population $[8,10]$.

\subsection{Dental caries experience}

Dental caries is a major concern for persons with Ol because of difficulties with physical activity for oral hygiene. The mean score $\mathrm{dmft} / \mathrm{DMFT}$ of 3.0/2.2 indicated a moderate level of dental caries experience in Ol sample. Our findings were in accordance with previous studies that highlighted oral problems among the OI population. Saeves et al. [10] described that although OI patients in Norway had regular dental visits and daily oral health habits, their oral status was not as good as compared to the general population. Differently from the findings of Saeves in Norway, none of the Vietnamese individuals with $\mathrm{Ol}$ received any restorative treatment for decayed teeth. The physical disability of persons with $\mathrm{OI}$ might influence their ability to visit a dentist for dental treatment; in addition, most of them were from healthcare centers that only focused on rehabilitation of Ol patients. The dental issues and lack of dental visits could accelerate caries development in Ol persons; however, the number of decayed teeth of Vietnamese people with Ol was lower compared to the general population in Vietnam [22]. This is possibly related to DGI presenting in persons with OI. In DGl dentition, the presence of obliterated dentinal tubules and pulp chamber can prevent penetration of harmful bacteria, although enamel has chipped away. This might explain that the missing teeth component in our study ( $\mathrm{mt} / \mathrm{MT}=1.3 / 0.3)$ resulted from hypodontia as aforementioned, not by the impact of caries. The shortcoming of our study is an absence the control group to compare with the Ol sample in evaluation the risk of oral problems. In addition, radiographic examination was not carried out for Ol participants to determine the reasons for missing teeth due to impacted teeth or hypodontia.

\section{CONCLUSION}

There was a high prevalence of dentinogenesis imperfecta and dental wear in the Vietnamese OI sample, especially in OI type III and IV. The occlusal features of Ol persons were determined with a high prevalence of class III, malocclusion, overjet, open bite, posterior crossbite, and missing teeth. The dental caries experience of persons with Ol was at a moderate level, and none of the study's subjects had received any dental restorations.

\section{CONFLICT OF INTEREST}

The authors declare no conflict of interest.

\section{AUTHOR CONTRIBUTIONS}

MSN: performed clinical studies, data acquisition, statistical analysis, and manuscripts writing, MS: analysis results, proofreading, $\mathrm{BH}$ : data acquisition, $\mathrm{KM}$ : data acquisition and interpretation of the results, SK: interpretation of the results, AM: data acquisition, TT: data acquisition and manuscript literature search, TJ: protocol, proofreading. 


\section{ACKNOWLEDGMENTS}

This study was supported by the Estonian Science Foundation grant ESF 9255, the Estonian Research Council IUT 20-46 and Eramus+ EDUSHARE projects.

\section{REFERENCES}

1. Rauch F, Glorieux FH. Osteogenesis imperfecta. Lancet 2004;363(9418):1377-1385. doi:10.1016/S0140-6736(04)16051-0. [Full text links] [PubMed] Google Scholar Scopus

2. Van Dijk F, Sillence D. Osteogenesis imperfecta: Clinica diagnosis, nomenclature and severity assessment. Am JMed Genet A. 2014;164A(6):1470-1481. doi:10.1002/ajmg.a.36545.

[Full text links] [CrossRef] [PubMed] Google Scholar Scopus

3. Andersen PE, Hauge M. Osteogenesis imperfecta: genetic, radiological, and epidemiological study. Clin Genet. 1989;36(4):250-255. doi:10.1111/j.1399-0004.1989.tb03198.x

[Full text links] [CrossRef] [PubMed] Google Scholar Scopus

4. Martin E, Shapiro JR. Osteogenesis imperfecta:epidemiology and pathophysiology. Curr Osteoporos Rep. 2007;5(3):91-97. doi:10.1007/s11914-007-0023-z.

[PubMed] Google Scholar Scopus

5. Sillence DO, Senn A, Danks DM. Genetic heterogeneity in osteogenesis imperfecta. J Med Genet. 1979;16(2):101-116. doi:10.1136/jmg.16.2.101.

[Full text links] [PubMed] Google Scholar Scopus

6. Warman ML, Cormier-Daire V, Hall $\mathrm{C}$, et al. Nosology and classification of genetic skeletal disorders: 2010 revision. Am J Med Genet A. 2011;155A(5):943-968. doi:10.1002/ajmg.a.33909.

[Full text links] [PubMed] Google Scholar Scopus

7. Chang P-C, Lin S-Y, Hsu K-H. The craniofacial characteristics of osteogenesis imperfecta patients. Eur J Orthod. 2007;29(3):232237. doi:10.1093/ejo/cjl035.

[Full text links] [CrossRef] [PubMed] Google Scholar Scopus

8. Nguyen MS, Binh HD, Nguyen KM, et al. Occlusal features and need for orthodontic treatment in persons with osteogenesis imperfecta. Clin Exp Dent Res. 2017;3(1):19-24. doi:10.1002/ cre2.53.

[Full text links] [CrossRef] [PubMed] Google Scholar Scopus

9. Rizkallah J, Schwartz S, Rauch F, et al. Evaluation of the severity of malocclusions in children affected by osteogenesis imperfecta with the peer assessment rating and discrepancy indexes. Am $J$ Orthod Dentofac Orthop. 2013;143(3):336-341. doi:10.1016/j. ajodo.2012.10.016.

[Full text links] [CrossRef] [PubMed] Google Scholar Scopus

10. Saeves R, Lande Wekre L, Ambjørnsen E, et al. Oral findings in adults with osteogenesis imperfecta. Spec Care Dentist. 2009;29(2):102-108. doi:10.1111/j.1754-4505.2008.00070.x.

[Full text links] [CrossRef] [PubMed] Google Scholar Scopus

11. Malmgren B, Norgren S. Dental aberrations in children and adolescents with osteogenesis imperfecta. Acta Odontol Scand. 2002;60(2):65-71. doi:10.1080/000163502753509446.

[Full text links] [CrossRef] [PubMed] Google Scholar Scopus

12. Majorana A, Bardellini E, Brunelli PC, et al. Dentinogenesis imperfecta in children with osteogenesis imperfecta: a clinica and ultrastructural study. Int J Paediatr Dent. 2010;20(2):112-118. doi:10.1111/j.1365-263X.2010.01033.x.

[Full text links] [CrossRef] [PubMed] Google Scholar Scopus
13. Shields ED, Bixler D, el-Kafrawy AM. A proposed classification for heritable human dentine defects with a description of a new entity. Arch Oral Biol. 1973;18(4):543-553. doi:10.1016/00039969(73)90075-7.

[CrossRef] [PubMed] Google Scholar Scopus

14. Binh HD, Maasalu K, Dung VC, et al. The clinical features of osteogenesis imperfecta in Vietnam. Int Orthop. 2017;41(1):21-29. doi:10.1007/s00264-016-3315-z.

[Full text links] [CrossRef] [PubMed] Google Scholar Scopus 15. Hooper SM, Meredith N, Jagger DC. The development of a new index for measurement of incisal/occlusal tooth wear. J Oral Rehabil. 2004;31(3): 206-212. doi:10.1046/j.0305182X.2003.01232.x

[Full text links] [CrossRef] [PubMed] Google Scholar Scopus

16. Lin $\mathrm{H}-\mathrm{Y}$, Lin S-P, Chuang $\mathrm{C}-\mathrm{K}$, et al. Clinical features of osteogenesis imperfecta in Taiwan. J Formos Med Assoc. 2009;108(7):570-576. doi:10.1016/S0929-6646(09)60375-2.

[Full text links] [PubMed] Google Scholar Scopus

17. Waltimo-Sirén J, Kolkka M, Pynnönen S, et al. Craniofacial features in osteogenesis imperfecta: a cephalometric study. Am J Med Genet A. 2005;133A(2):142-150. doi:10.1002/ajmg.a.30523. [Full text links] [CrossRef] [PubMed] Google Scholar Scopus 18. Malmgren B, Andersson K, Lindahl K, et al. Tooth agenesis in osteogenesis imperfecta related to mutations in the collagen type I genes. Oral Dis. 2017:23(1):42-49. doi:10.1111/odi.12568. [Full text links] [CrossRef] [PubMed] Google Scholar Scopus 19. Scalia G, Schwartz S, Rauch F, et al. The Relationship between dental occlusion, arch width and depth in children with osteogenesis imperfecta. Submitted to the J Orthod.

Google Scholar

20. Nguyen SM, Nguyen MK, Saag M, et al. The need for orthodontic treatment among Vietnamese school children and young adults. Int J Dent. 2014;2014:132301. doi:10.1155/2014/132301.

[Full text links] [CrossRef] [PubMed] Google Scholar Scopus

21. O'Connell AC, Marini JC. Evaluation of oral problems in an osteogenesis imperfecta population. Oral Surg Oral Med Oral Pathol Oral Radiol Endod. 1999;87(2):189-196. doi:10.1016/s10792104(99)70272-6.

[Full text links] [CrossRef] [PubMed] Google Scholar Scopus

22. Nguyen TT, Nguyen BBT, Nguyen MS, et al. Effect of School Oral Health Promotion Programme on dental health and health behavior in Vietnamese school children. Pediatr Dent $J$. 2016;26(3):115-121. doi: 10.1016/j.pdj.2016.09.001.

[CrossRef] Google Scholar Scopus 


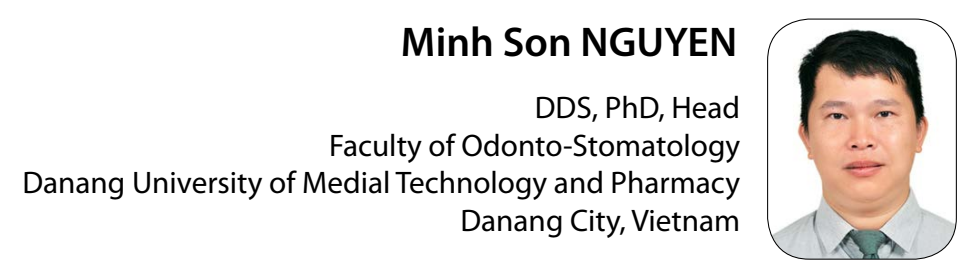

Minh Son Nguyen was awarded a PhD degree in 2018 at the Institute of Dentistry, University of Tartu. Currently, he is the Head of the Faculty of Odonto-Stomatology and a lecturer at the Danang University of Medical Technology and Pharmacy, Vietnam. Dr. Nguyen has published peer-reviewed articles related to temporomandibular disorders, prosthodontics, and community dental health.

\section{Questions}

\section{Osteogenesis imperfecta is a genetic mutation affecting}

$\square$ a. Connective tissue;

ab. Bone;

ac. Eyes;

ad. Dentition.

\section{Which type of osteogenesis imperfecta cannot be observed in living persons?}

Da. Type l;

ab. Type II;

ac. Type III;

ad. Type IV.

3. The high prevalence of malocclusion that can be observed in persons with $\mathrm{Ol}$ is related to

पa. Angle's class l;

ab. Angle's class II, division I;

uc. Angle's class II, division II;

ud. Angle's class III.

4. Which type of dentinogenesis imperfecta is associated with osteogenesis imperfecta?

Da. Only DGI type l;

口b. DGl type I and type II;

口c. DGI type I and type III;

ad. DGI type II and type III. 